\title{
Assessment of friction pair elements condition based on changes in the geometric surface structure isotropicity degree
}

\author{
Maciej Matuszewski ${ }^{1, *}$, Matgorzata Słomion ${ }^{1}$, Adam Mazurkiewicz $^{1}$ and Danil Yu. Pimenov ${ }^{2}$ \\ ${ }^{1}$ University of Science and Technology in Bydgoszcz, Faculty of Mechanical Engineering, 85-796 Bydgoszcz, Poland \\ ${ }^{2}$ South Ural State University, Department of Automated Mechanical Engineering, Lenin Prosp. 76, Chelyabinsk 454080, Russia
}

\begin{abstract}
This paper regards the possibility of using the degree of the surface isotropicity to assess the condition of the surface layer friction pair elements. The analysis is based on certain changes in operational and technological surface layer. The methods of constituting the surface layer have been characterized due to the features of geometric surface structure as well as the problem of assessing the condition of surface in terms of functional features and tribological characteristics.

The evaluation of the occurring changes in the surface layer have been conducted by performing tribological tests and for descript condition of surfaces the degree of surface isotropicity and weight loss of specimens have been adopted. Whereas the assessment of technological state of the surface layer has been carried out for the surface after its coating. Based on the analysis, it has been found that the use for assessment the condition of surface layer and the degree of the surface isotropicity are useful and it is an alternative way or supplement to classical adoption of a properly selected set of roughness parameters to evaluate the potential functional characteristics of friction couples surfaces.
\end{abstract}

\section{Introduction}

Each technical object has a set of functional qualities, such as: reliability, wear resistance, fatigue strength, resistance to movement, corrosion resistance, etc. Based on numerous studies, it may be concluded that these characteristics depend on the greatest extend of the condition of the surface layer, especially on the parameters characterizing the geometric surface structure [1-8]. Due to the fact that most these damages happen inside of the surface layer, the proprieties enlarging- resistance on destructive working extortions during machine and devices operation are given rught to the layer. Therefore, the surface layer is the subject of researches conducted in many scientific centers: domestic and foreign ones. It has been confirmed that the mechanism and intensity of wear process depend on features of the surface layer, established as a result of technological processes [9-12]. Affected by these factors (for example: mechanical, thermal, chemical and electrical) while the friction pair is working, the surface layer is changing. These changes usually cause a different loss degree of kinematic pairs ability to work to fulfill structurally accepted functions.

Shaping desirable features of the surface layer, especially the geometric surface structure, already in the manufacturing process is a very important problem due to the ability of kinematic pair elements to fulfil the technical object functions adopted in the construction process as long as possible. The surface layer produced in a technological process has a significant impact on functional characteristics, which determines the durability of the entire machine. It should be remembered that tribological processes should be always considered for a pair of elements- depending on the association with the intensity of the wear process and even its mechanism may differ. The characteristics of the surface layer are largely determined by stereometric parameters, which describe surface stereometric structure, more often called the geometric surface structure. They are most commonly used to describe changes in the surface layer. They are characterized by continuous changes during the manufacturing and operating process and thus describe well the current state of the surface layer. During the cooperation of elements in a friction pair, their surface is in the interaction and therefore the geometric surface structure has a significant impact on functional features and tribological characteristics [11, 13-18].

Taking into account the phases of the machine existence ("life"), two forms of surface layer and its elements could be distinguished: technological and operational. They occur as follows:

- in a phase of construction, design, machine elements manufacturing and their assembly (technological surface layer),

- in a phase of the machining operation (operational surface layer).

There is no ambiguous information in the literature how should be surface layer elements classify during the warehousing and transport phase, into the operational surface layer or technological surface layer. On the one hand, it is not yet affected by external operational forces, so there are no grounds to include it in the operational surface layer, on the other- the manufacturing process has been already completed- so it is no longer a technological surface layer.

In this work, the degree of surface isotropicity was assumed to assess the condition of friction pair elements.

\section{Methods of the surface layer constitute}

There are many methods for constituting the technological surface layer, as well as the number of different treatments and technological operations- the components of technological processes of machine elements. A very general division of the surface layer creating methods in which the criterion of division is the increase of material was proposed in [10, 19-22] studies. According to this classification, the methods of the surface layer constituting are divided into:

${ }^{*}$ Corresponding author: matus@utp.edu.pl 
- weight- loss method- realized by reducing object dimensions, e.g. machining, erosion, blasting work,

- loss- free method- implemented without reducing the dimensions of the object, e.g. heat treatment, plastic working, implantation, PVD, CVD,

- incremental method- realized by increasing the dimensions of the object, e.g. electrolytic coating.

The examples of listed treatments in each of the cited groups present the fact that the increase is generally treated, i.e. it might be positive, negative or neutral. In addition, it may be mass or geometric. Within the division adopted in this way, all known techniques used in manufacturing processes shall be classified at least into one of the cited groups . It should be noted that the mass increase is not always accompanied by a change in the linear dimension and vice versa. Representative examples in this regard may be:

- implantation - weight gain without geometric dimension changing,

- burnishing - changing the geometric dimension without mass changing.

Based on the above considerations, it could be concluded that the technological surface layer is dynamic- its condition changes after each cut or operation. However, the functional characteristics of machine is determined by the condition of the surface layer elements after last operation, that is why this condition should be adopted as the technological surface layer of the finished element and then it does have a static character.

The weight-loss and loss-free treatment are the basic manufacturing techniques used to shaping elements of the technical devices.

The most widespread, because of its great universality and accuracy of shaping is the cutting process based on the model of removing the material allowance in a form of chips by the cutting tool edge. The total share of machining in the machine industry is currently estimated at about $50 \%$ and according to the forecasting by the International Institution for Production Engineering Research (CIRP) this share will be significant for a long time. It results in growing possibilities of machining applications and received accuracy [19].

Dynamically developing techniques for modifying the condition of the geometric surface structure of frictional cooperating elements at the production stage are coating application techniques by the physical or chemical methods. A thin- as low as a few micrometers- ceramics layer (most often) reduces the intensity of the wear process. One of the reasons for this phenomenon is the fact that applied coating has a significantly higher hardness than the substrate and thus more resistant to the effects of external operational forces. Application of the coating causes changes in the surface structure, which may also contribute to reduction of the intensity of the wear process.

Changes of the geometric surface structure condition are dependent on a coating method. Physical vapour deposition (PVD) and chemical vapour deposition (PVD) are basic methods for getting thin layers.

Conventional (i.e. not supported) techniques for producing nanocrystalline layers by CVD methods depends on the coating material setting from the gaseous phase as a consequence of chemical reactions occurring the substrate surface or in its vicinity. Temperature, chemical composition and conditions for flow of reagents through the retort are the parameters that affect this process.

The processes of coatings physical vapour deposition (PVD) consist of changing the physical state of the coating material based on vacuum techniques. There are two basic methods to change the physical material state from which the coating will be made:

- evaporation or sublimation,

- sputtering influenced by non-thermal physical excitations.

PVD coatings, like CVD, significantly increase wear resistance and thus durability. The application is also similar, i.e. mainly these are coatings applied to cutting tools and frictional cooperating surfaces.

\section{Transformation of the surface layer}

The features of technological surface layer, constituted as a result of the implementation of the assumed technological process, significantly depend on kind of operations and their parameters that occur in a manufacturing process. In turn, the course of wear depends on the features of the technological surface layer- its mechanism, intensity, effects and consequently the machines durability. Characteristics of the technological surface layer are changing after each operation and treatment undertaken, so it might be said that it is dynamic. These changes concern both, the inside of surface layer and its top and the whole process is called the transformation of the technological surface layer. However, the functional characteristics of machine is determined by the condition of the surface layer elements after last operation, that is why this condition should be adopted as the technological surface layer of the finished element and then it does have a static character.

The effect of kinematic excitations is mainly observed in the geometric surface structure. These forces are affected by kinematic machining parameters. The shape and placement of machining marks after each technological operation, i.e. the directionality of the geometric surface structure, depend on their value and relation between the movements of the tool and workpiece. Figure 1 shows examples of surface structures obtained by various finishing methods. 
a)

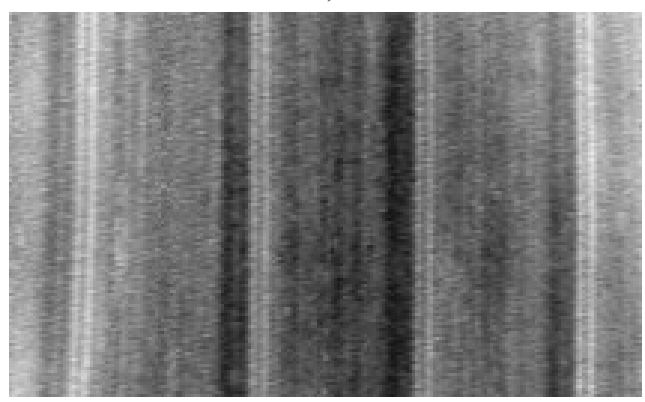

b)

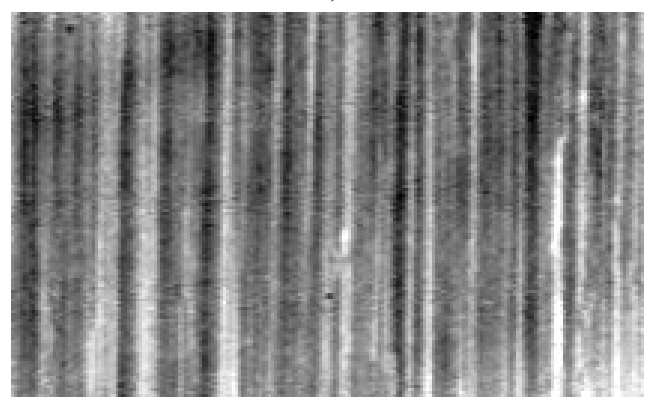

c)

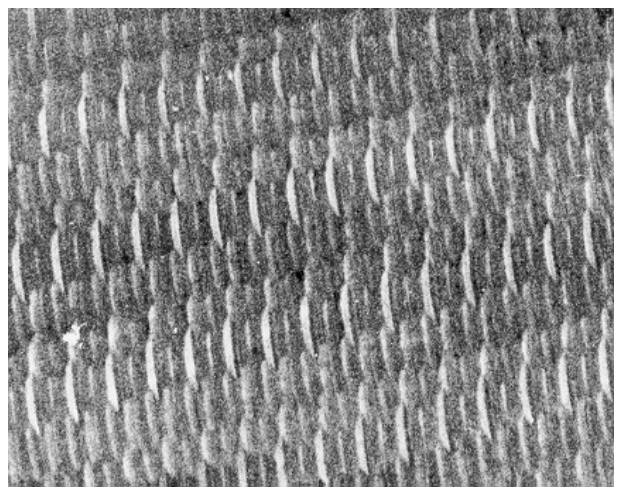

Fig. 1. Surface structures after finishing: a) turning, b) grinding, c) mill-turning.

The presented drawings show that the structures obtained by turning and grinding are anisotropic, while in the case of hybrid machining which is milling, the structure is clearly isotropic. As the operational characteristics of technological surface layer is adopted those which characterize the condition of surface layer after completion of the whole technological process. Transient parameters describing the state of surface layer are significant, only if they cause any reactions in following technological operations.

Since the moment of beginning of operation process of a technical object, right from the time when it begins to affect the object and its component elements the external operational forces, the technological surface layer is transformed into operational surface layer and the process of transformation begins. Similarly, like in the case of technological surface layer transformation, it is a dynamic process. The state of operational surface layer is changing during the whole phase of machines and devices operation. The common feature of transformation, both technological surface layer and operational surface layer, is their dynamic character. Nevertheless, in case of technological surface layer, with regard of the course of operation process, a really essential is the state at the end of production, however for operational surface layer essential is its current state.

For description of state and changes in the surface layer of machine elements, and so to delimitate also the functional characteristics of machines, the most often the different parameters of roughness are applied [1, 23-26]. Undoubtedly, they are important for both the splitting and concentrated contact of cooperating surfaces, however the inference of the condition of the surface layer only based on roughness parameters may not reflect the surface functional behaviour the specific external forces.

\section{The issue of evaluating the status of the geometrical surface structure in the aspect of functional characteristics}

One of the fundamental objectives of geometrical surface structure metrology in addition to control is to anticipate and optimize its functional features of the surface which are related to its shape. An important step in the analysis of the surface is to choose the appropriate parameters which lead to proper conclusions, whether the determinate geometric structure can provide the necessary functional characteristics of surface. Facilitating factor in choosing parameters for the geometric surface structure analysis is to consider the working conditions and resulting goals [11, 15, 18, 21, 26,27]. These conditions might be, for example:

- should the surface hold the lubricant?

- will the material be removed from the surface?

- will the surface tension occur?

It should be clear that to take an advantage of all parameters to access the geometric surface structure with respect to its functional characteristics is not realistic. On the other hand, the simplification is to attempt a geometric surface structure using only one parameter, which is unfortunately very common in industrial practice. The development of computer-aided, precision measuring and digital apparatus for surface analysis favors the creation of many parameters used to description the geometric surface structure. However, there is a tendency to harmonize and reduce the number of privileged parameters in national standards these days. Creating a universal set of parameters, equally useful for 
surfaces with various functional assignment is not possible in practice. Even with similar values of basic amplitude parameters, the other parameters may differ significantly. The surface assessment may be then ambiguous, because they shall have similar or the same roughness parameter value and different functional characteristics. Figure 2 shows an example comparison of Ra roughness parameter for different types of profiles.

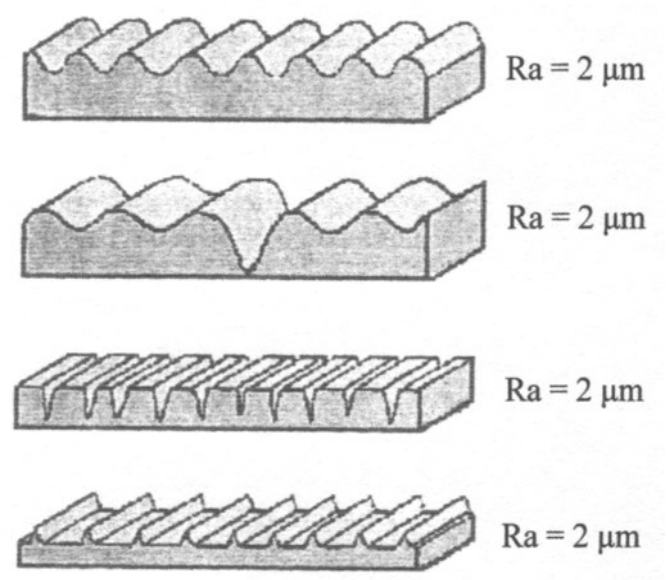

Fig. 2. Comparison of profiles with the same Ra value [27].

Despite the same value of the Ra roughness parameter, presented profiles will have different operational features. For each of analyzed surfaces should be decided separately which features of the geometric surface structure are important in terms of functional characteristics and which roughness parameters give the most appropriate information. No standards exist that stating in which cases particular parameters should be used. Only relevant recommendations can be found in the literature to selecting parameters for evaluation the functional characteristics.

In figure 3 the examples of roughness parameters comparison for different surfaces determining different functional characteristics are shown.

a)

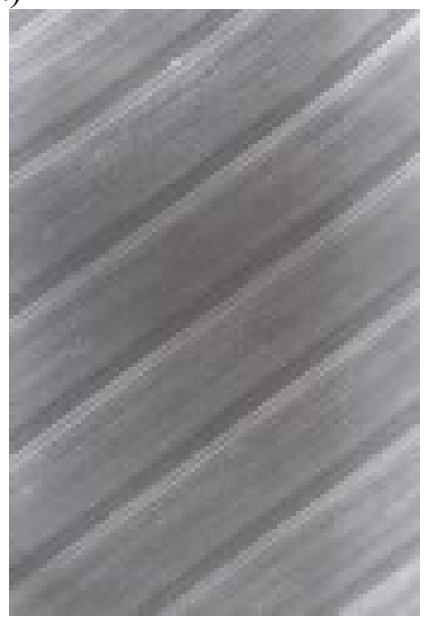

b)

$$
\begin{aligned}
& \mathrm{Ra}=1,15 \mu \mathrm{m} \\
& \mathrm{Rz}=5,31 \mu \mathrm{m} \\
& \mathrm{Rt}=5,8 \mu \mathrm{m} \\
& \mathrm{Rp}=3,47 \mu \mathrm{m} \\
& \mathrm{Rk}=3,02 \mu \mathrm{m} \\
& \mathrm{Rpk}=1,45 \mu \mathrm{m} \\
& \mathrm{Rvk}=0,51 \mu \mathrm{m}
\end{aligned}
$$

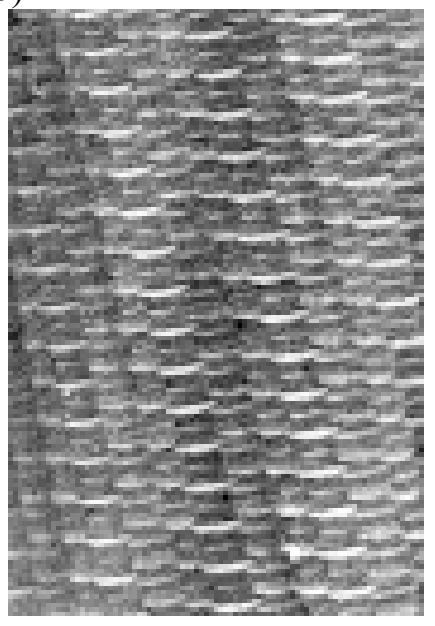

$\mathrm{Ra}=1,21 \mu \mathrm{m}$

$\mathrm{Rz}=5,73 \mu \mathrm{m}$ $\mathrm{Rt}=6,31 \mu \mathrm{m}$ $\mathrm{Rp}=3,94 \mu \mathrm{m}$ $\mathrm{Rk}=3,24 \mu \mathrm{m}$ $\mathrm{Rpk}=1,21 \mu \mathrm{m}$ $\operatorname{Rvk}=3,81 \mu \mathrm{m}$

Fig. 3. View and parameters describing the geometrical surface structure of the machined surfaces: a) turning - for $\mathrm{vC}=18.5 \mathrm{~m} \cdot \mathrm{s}-1$ and $\mathrm{f}=0.17 \mathrm{~mm} \cdot$ rev-1 (aluminum), b) mill-turning - for $\mathrm{vC}=2,1 \mathrm{~m} \cdot \mathrm{s}-1$ and $\mathrm{f}=0.75 \mathrm{~mm} \cdot \mathrm{rev}-1$ (steel)

The presented comparison shows that the amplitude parameters, which are commonly used to describe tribological characteristics, and which were the first parameters taken into account to assess the surface, do not quite accurately inform about the possible behavior of the surfaces in a kinematic pair. Only the analysis of the bearing capacity curve parameters differentiates frictional association behavior. A surface with a much higher Rvk value will be the surface with greater oil holding ability and at the same, because of the lower value of Rpk, although not so distinctly, it will be more wearability in initial phase of cooperation.

Selection of various roughness parameters for the assessment functional characteristics and to appoint tribological characteristics is carried out, i.a. based on researches, statistical relationships between them and availability of apparatus. As already shown, the selected parameters describing surface structure in the aspect of its functional characteristics cannot be always clearly classify. Surface characteristics based on roughness parameters are additionally difficult because of the parameter values variability at the different surface places which resulting from the machining process. For each parameter the range of its value is different, usually larger for longitudinal parameters than for height ones and in practice the possible spread can reach up to several percent. For these reasons, this selection will always be burdened with more or less subjectivity. In functional characteristics evaluation is always recommended to use a set of appropriately selected parameters, which is often complicated [12, 15, 18, 21, 24, 26]. Even in some studies concerning the functional characteristics assessment besides selected for evaluation parameters it is possible to find an information 
about processing method. Therefore, some beneficial solution is to use mathematical functions, which describe the surface in a frequency method, for delineate the geometric surface structure $[22,28]$. This procedure seems to be free from the fault of subjective parameters selection model and with the dynamic development of computer techniques supporting engineering activities, determining these functions is not a complicated activity. In addition, frequency analysis allows the assessment of the geometric surface structure, independently from the type of treatment [22, 28]. The most reasonable and precise in terms of mathematical description, seems to be the method based on the analysis of surface autocorrelation function or spectral power density $[22,28]$. In practice, one of these functions can be used for analysis, because the spectral power density function is a Furier transformation of the surface autocorrelation function. In general, this function is a measure of dependence between value of data in one location and its value in the other. Application of space-frequency functions is becoming more and more common not only to assess changes in the surface layer in terms of their functional characteristics. The frequency analysis is the source of information about the manufacturing process, e.g. as a carrier of information about condition of the cutting tool blade or for monitoring the technological process based on e.g. the value of cutting forces and their components [20, 21, 24, 25].

The graphic form of the autocorrelation function can be presented, e.g. in the form of so called rose of directions [18]. This rose determine main directions of surface formation. From the graph (Fig. 4.) can be inferred only qualitatively about the nature of surface which is shown in Figure 5. However, from the function and indirectly from the graph you can determine the quantitative parameter - the degree of surface isotropicity, that is, the degree of orientation - ordering - traces of machining or wear.

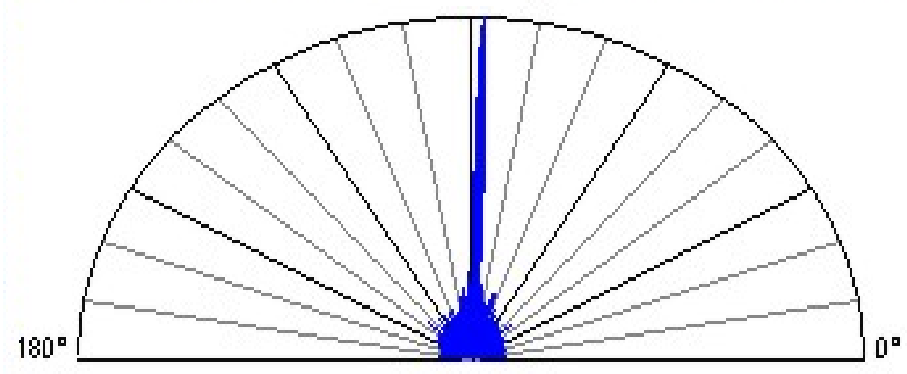

Fig. 4. Example of surface structures directions rose- degree of isotropicity: $\mathrm{Iz}=8.01 \%$.

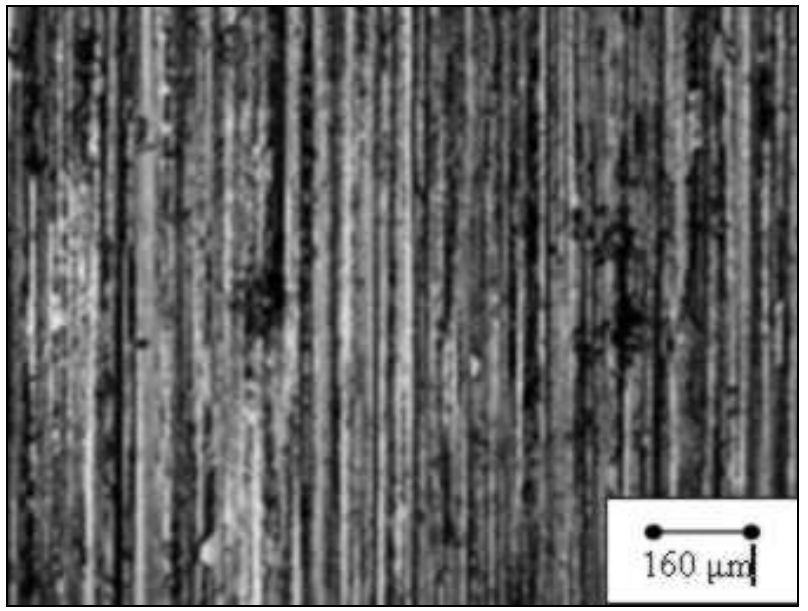

Fig. 5. Image of the geometric surface structure obtained by a confocal laser scanning microscopy.

\section{Results}

In order to verify the usefulness of using the degree of isotropicity for the quantitative assessment of occurring changes in the surface layer of cooperating surfaces, experimental tests have been carried out. They have been made in two stages. First, tribological tests were carried out, so the usefulness of applying the degree of isotropicity to assess changes in the operational state of the surface layer was analysed. For the quantitative assessment of changes, the degree of isotropicity and additional weight loss were adopted as a direct measure of wear. During surface cooperation, there is a continuous change in the shape of the geometric surface structure, so these tests are a good tool for verifying the suitability of using a degree of surface isotropicity to describe the shape of the structure, which in turn determines the surface usability characteristics. The weight loss and changes in the degree of isotropicity during the transformation of the surface layer reflect well the current state of the surface layer, and thus the current functional characteristics. The weight loss takes place on the whole surface, so it applies to changes in the entire area of cooperating surfaces. Structure isotropicity also applies to the entire area, it is not local. Conditions during tribological tests were mostly adopted as permanent. Specimens with counter-specimen cooperated in the lubricating medium, which was machine oil (L-AN 68), and the values of operational parameters were as follows: relative motion speed: $2,9 \mathrm{~m} / \mathrm{min}(0,05 \mathrm{~m} / \mathrm{s})$, cooperation angle between characteristic directionality of specimens and counter-specimen was $0^{\circ}$. Specimens were 
made of $102 \mathrm{Cr} 6$ steel, whereas counter-specimen was made of X210Cr12 steel. Counter-specimen hardness (60 HRC) exceeded the hardness of the specimens so that changes took place primarily on the specimens surfaces. Hardness values of the specimens were: 30, 40 and 50 HRC. Specimens worked at 300, 450 and $600 \mathrm{~N}$ loads, which corresponded to the theoretical pressures in the contact zone: $1 ; 1.5$ and $2 \mathrm{MPa}$. Measurement points were adopted for friction distance at which the observed changes were the most intense and amounted to: 100, 200, 300, 400, 500 and $600 \mathrm{~m}$.

Figure 6 presents changes in the degree of isotropicity of the geometric surface structure of tested specimens and loss of their mass as a function of friction distance.

a)

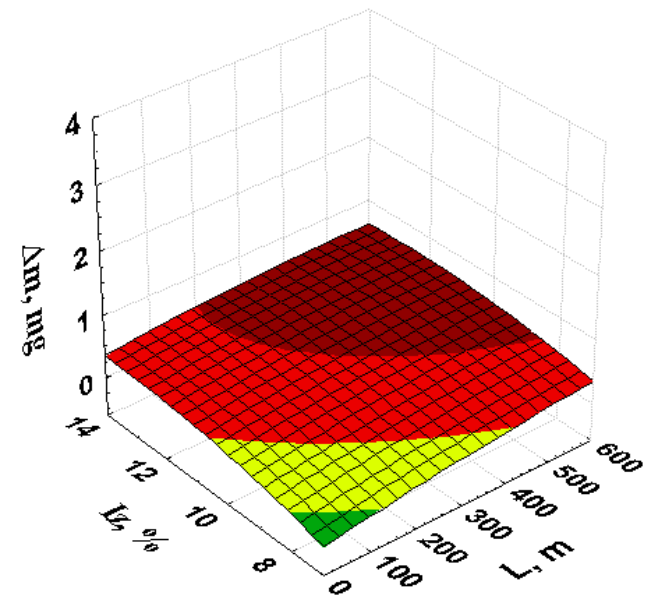

b)

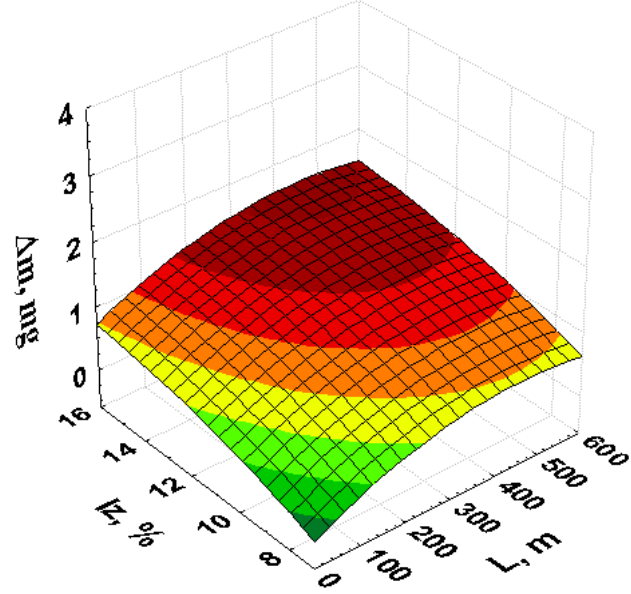

c)

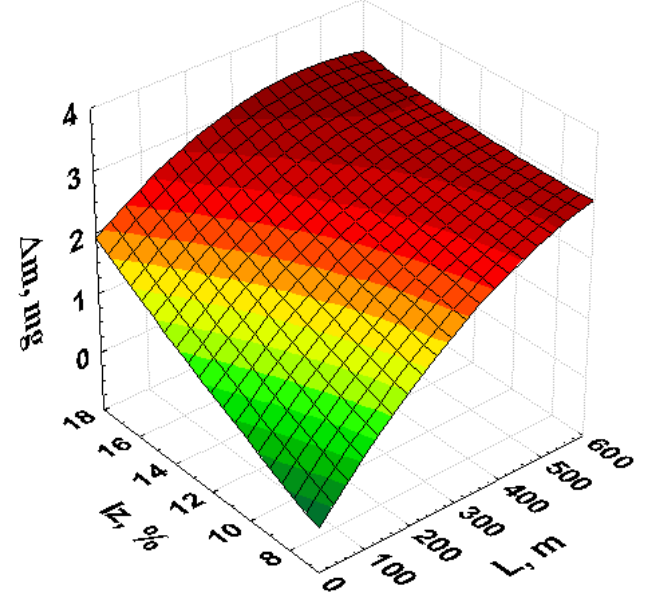

Fig. 5. Relations between mass loss of specimens $\Delta m$, isotropicity degree $I z$ and friction distance $L$ for: a) $\mathrm{F}_{1}=300 \mathrm{~N} \mathrm{i}_{3}=50 \mathrm{HRC}$, b) $\mathrm{F}_{2}=450 \mathrm{~N} \mathrm{i} \mathrm{H}_{2}=40 \mathrm{HRC}$, c) $\mathrm{F}_{3}=600 \mathrm{~N} \mathrm{i} \mathrm{H}_{1}=30 \mathrm{HRC}$.

Based on the results presented in the drawings it shall be stated that the analysed factors and individual relations confirmed impact of the isotropicity degree on the surface layer transformation. The greatest changes are observed for external operational factors $(\mathrm{F}=600 \mathrm{~N}$ and $\mathrm{H}=30 \mathrm{HRC})$, which as expected, should cause the most intense changes, and the smallest- also as expected, for the external operational factors: $\mathrm{F}=300 \mathrm{~N}$ and $\mathrm{H}=50 \mathrm{HRC}$. With the least intense changes in the surface layer, also changes in isotropicity and mass are clearly noticable. Changing the degree of isotropicity is a change in the shape of the geometric surface structure. The greater the degree of isotropicity, the distribution of characteristic elements of structure is more random. They are "flattened" and the symmetry of this configuration increases (the degree of isotropicity increases). Single peaks and microroughness ridges are subject to partial or complete wear. Due to the configuration structure becomes more symmetrical, which can have a positive effect on the distribution of the lubricating medium and as a consequence on the resistance to motion.

Based on carried out studies it could be concluded that dependence of the operational surface layer transformation course from the degree of isotropicity, which is characterizing the entire potential contact is beneficial due to the designated tribological characteristics.

At the second stage of tests the usefulness of applying the degree of isotropicity to assess changes in the technological surface layer state by coating were analysed. Primary surfaces with a clear lack of structure orientation (isotropic) and surfaces with visible directionality of the geometric surface structure (anisotropic) were observed and compared with the state after coating. The topography of these surfaces is shown in Figures 7 and 8 , and the values of measured parameters are summarized in Table 1. Isotropic surfaces of tool bit made of self-bonded carbide (fig. 7.), while anisotropy was characterized by ground surfaces of a twist drill blade made of $102 \mathrm{Cr} 6$ tool steel (fig. 8). In both analysed cases, the coating was made of titanium nitride (TiN). 
a)

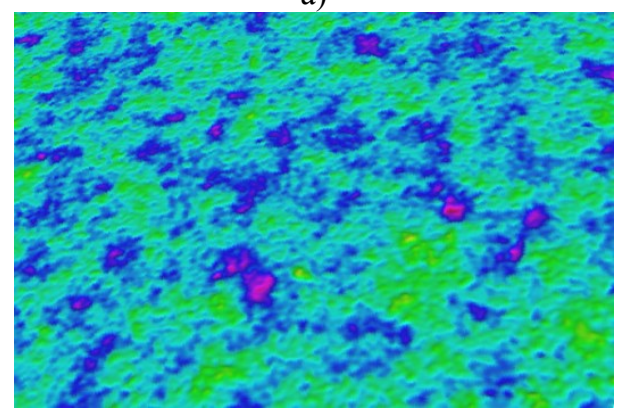

b)

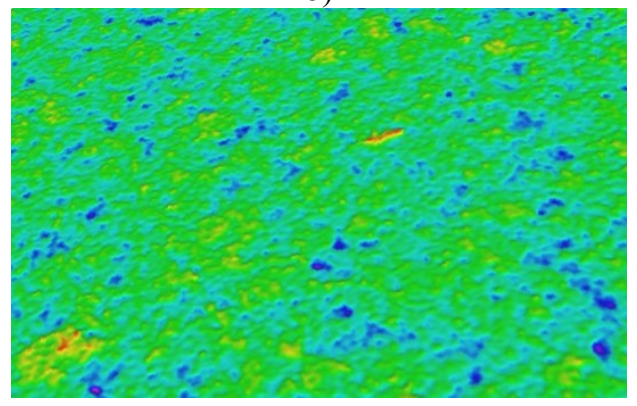

Fig. 7. Topography of self-bounded carbide surface: a) without coating, b) with TiN coating.

a)

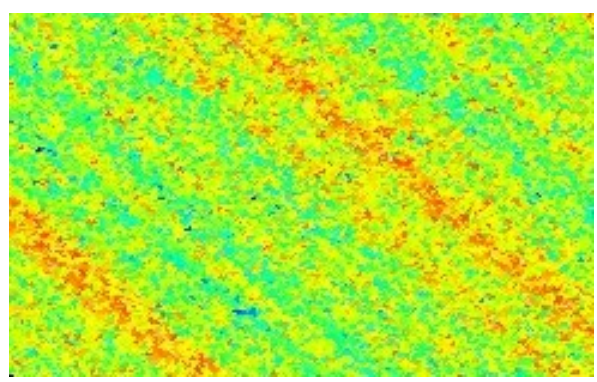

b)

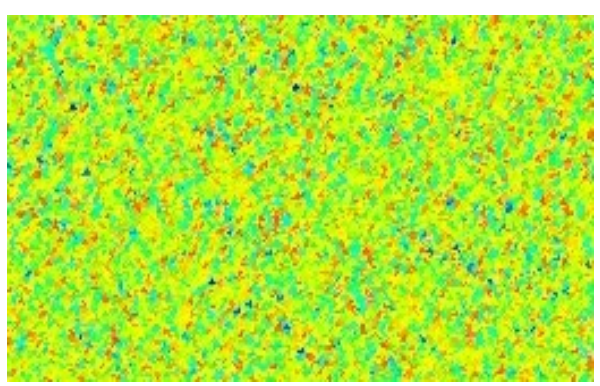

Rys. 8. Topography of the twist drill surface made of $102 \mathrm{Cr} 6$ tool steel: a) without coating, b) with TiN coating.

Table 1. Calculated values of the geometric surface structure parameters

\begin{tabular}{|c|c|c|c|c|}
\hline \multirow{2}{*}{$\begin{array}{c}\text { Measured } \\
\text { calculated } \\
\text { parameter }\end{array}$} & \multicolumn{3}{|c|}{ Substrate material } \\
\cline { 2 - 5 } & \multicolumn{2}{|c|}{ self-bounded carbide } & without coating & coated \\
\cline { 2 - 5 } & without coating & coated & 0,39 & 0,34 \\
\hline $\mathrm{Ra}, \mu \mathrm{m}$ & 0,26 & 0,2 & 0,45 & 0,39 \\
\hline $\mathrm{Rq}, \mu \mathrm{m}$ & 0,33 & 0,26 & 1,5 & 0,94 \\
\hline $\mathrm{Rt}, \mu \mathrm{m}$ & 3,81 & 2,94 & 0,42 & 85,38 \\
\hline $\mathrm{Rpk}, \mu \mathrm{m}$ & 0,3 & 0,25 & 57,4 & 85,2 \\
\hline $\mathrm{Iz}, \%$ & 83,3 & 88,3 & \multicolumn{2}{c}{ tool steel $102 \mathrm{Cr} 6$} \\
\hline
\end{tabular}

Based on the obtained results it shall be concluded that the surfaces with the coating are characterized by a lower value of roughness parameters than before coating and for all analysed parameters. In case of isotropicity, its varied change is observed after applying the ceramic coating to the tested materials. In case of surfaces with a clear lack of structure orientation (self-bounded carbide) changes are insignificant, whereas in case of surfaces with high anisotropicity (tool steel) changes are pronounced. In this case, the stereometric shape of surface after applying coating changed significantly, which reflects the change in the degree of isotropicity. On the other hand, roughness parameters do not characterize changes in shape, so they will not reflect well the changes in the functional characteristics of a friction pair consisting of such elements.

Based on the obtained tests it must be stated that determining the technological surface layer condition, which determines the potential functional characteristics, by using the degree of isotropicity may be beneficial due to the possibility of controlling the technological process with tribological criteria.

\section{Summary}

The usefulness of adopting the degree of surface isotropicity to assess the condition of the surface layer of cooperating friction pair elements and usefulness for assessing the condition of the surface layer at the stage of shaping desired characteristics of the geometric surface structure during the manufacturing process has been found on the basis of experimental research and analysis. Adopting the degree of isotropicity to assess the surface stereometric shape is an alternative or supplement method to the classic adoption of a properly selected set of roughness parameters, or individual parameters for the evaluation potential functional characteristics of the frictional surfaces couples. In addition, due to the possibility of subjective selection to assess the state of the surface structure roughness parameters, the use of the degree of surface isotropicity for this assessment may be a more advantageous solution, not loaded to the fault of the subjective selection model of parameters.

\section{References}

1. J. H. Horng, J. F. Lin, K. Y. Li, Effect of surface roughness on stell roller scuffing. Wear, 184, 203-212 (1995)

2. T. Kałaczyński, M. Łukasiewicz, J. Musiał, R. Polasik, M. Szczutkowski, N. Dluhunovych, J. Wilczarska, T. Kasprowicz: Analysis of the diagnostic potential research thermovision in the technical state of combustion engine 
injectors assessment, 24th International Conference Engineering Mechanics 2018, Svratka, Czech Republic, Book of full texts, Institute of Theoretical and Appiled Mechanics of the Czech Academy of Sciences, Prague, 357-360 (2018)

3. J. Krawczyk, Tribological properties of selected structural steels (Właściwości tribologiczne wybranych stali konstrukcyjnych). Tribologia, 4, 223-233 (2010)

4. E. Mańka, M. Słomion, M. Matuszewski, Constructional features of ropes in functional units of mining shaft hoist. Acta Mechanica et Automatica, 12, 1, 66-71 (2018)

5. M. Matuszewski, T. Mikołajczyk, D. Yu. Pimenov, M. Styp-Rekowski, Influence of structure isotropy of machined surface on the wear process. International Journal of Advanced Manufacturing Technology, 88, 9, $2477-2483$ (2017)

6. M. Matuszewski, M. Styp-Rekowski, Influence of texture direction of kinematic pair elements surfaces on service operated layer transformation. Tribologia 4, 87-97 (2006)

7. J. Musiał, Ł. Muślewski, M. Pająk, A. Grządziela, Analysis of vibration time histories in the time domain for propulsion systems of minesweepers. Journal of Vibroengineering 17, 3, 1309-1316 (2015)

8. M. Pająk, Ł. Muślewski, M. Pająk, B. Landowski, A. Grządziela, Fuzzy identification of the reliability state of the mine detecting ship propulsion system. Polish Maritime Research, 1 (101), 26, 55-64 (2019)

9. T. Burakowski, The importance of surface engineering in tribology (Znaczenie inżynierii powierzchni w tribologii). Tribologia, 4, 1097-1111 (2002)

10. T. Burakowski, T. Wierzchoń, Metal surface engineering (Inżynieria powierzchni metali), (Publ. WNT, Warszawa, 1995)

11. R. Górecka, Z. Polański, Metrology of the surface layer (Metrologia warstwy wierzchniej), (Publ. WNT, Warszawa 1983)

12. I. M. Hutchings, Tribology. Friction and wear of engineering materials, (Elsevier, Cambridge, 1992)

13. A. Bustilo, D. Yu. Pimenov, M. Matuszewski, T. Mikołajczyk, Using artificial intelligence models for the prediction of surface wear based on surface isotropy levels. Robotics and Computer Integrated Manufacturing, 53, 5, 215-227 (2018)

14. M. Łukasiewicz, T. Kałaczyński, J. Musiał, J. Shalapko, Diagnostics of buggy vehicle transmission gearbox technical state based on modal vibrations. Journal of Vibroengineering, 16, 6, 3137-3145 (2014)

15. G. W. Stachowiak, A. W. Batchelor, Engineering tribology, (Butterworth-Heinemann, Great Britain, 2001)

16. M. Styp-Rekowski, Geometrical constructional features of special rolling bearings against their exploitational properties, Proceedings of IV ${ }^{\text {th }}$ Symposium INTERTRIBO '90, C, 93-96 (1990)

17. M. Styp-Rekowski, E. Mańka, M. Matuszewski, M. Madej, D. Ozimina, Tribological problems in shaft hoist ropes wear process. Industrial Lubrication and Tribology, 67, 1, 47-51 (2015)

18. P. Pawlus, Surface topography: measurement, analysis, impact (Topografia powierzchni: pomiar, analiza, oddziatywanie), (Publ. Rzeszow University of Technology, Rzeszów, 2006)

19. W. Grzesik, Basics of cutting metal materials (Podstawy skrawania materiałów metalowych), (Publ. WNT, Warszawa, 1998)

20. W. Lubimow, K. E. Oczoś, Selected issues of shaping surface irregularities in machining processes (Wybrane zagadnienia ksztattowania nierówności powierzchni w procesach obróbkowych). Mechanik, 3, 81-84 (1997)

21. B. Nowicki B., Geometric structure: surface roughness and waviness (Struktura geometryczna: chropowatość $i$ falistość powierzchni), (Publ. WNT, Warszawa, 1991)

22. K. E. Oczoś, W. Lubimow, Surface geometric structure (Struktura geometryczna powierzchni), (Publ. Rzeszow University of Technology, Rzeszów, 2003)

23. J. Raja, Field testing of machine tool diagnostic techniques using surface metrology. Annals of CIRP, 32, 503-506 (1983)

24. B. G. Rosen, R. Ohlsson, J. Westberg, 1995. Interactive surface modelling, an implementation of an expert system for specification of surface roughness and topography. International Journal of Machine Tools and Manufacture, 35, 317-324 (1995)

25. D. J. Whitehouse, Process and quality control using surface finish. Proceedings $6^{\text {th }}$ Symposium IMEKO Metrology for quality control in production, Vienna, 699-710 (1998)

26. J. Williams, Engineering tribology, (Cambridge University Press, Cambridge, 2005)

27. M. Wieczorowski, A. Cellary, J. Chajda, A guide to measuring surface roughness, or roughness and more (Przewodnik po pomiarach nierówności powierzchni czyli o chropowatości i nie tylko). (Publ. Poznan University of Technology, Poznań, 2003)

28. K. E. Oczoś, W. Lubimow, Determinism and randomness of surface geometric structures (Determinowość $i$ losowość struktur geometrycznych powierzchni (SGP)). Pomiary Automatyka Kontrolna, 10, 2002, 4-6 (2002) 